\title{
Reactivity and Selectivity of Bowl-Shaped Polycyclic Aromatic Hydrocarbons: Relationship to $\mathrm{C}_{60}$
}

\author{
Yago García-Rodeja ${ }^{[\mathrm{a}]}$ Miquel Solà,${ }^{[\mathrm{b}]}$ F. Matthias Bickelhaupt,${ }^{[\mathrm{c}]}$ and Israel \\ Fernández ${ }^{[\mathrm{a}], *}$
}

[a] Mr. Y. García-Rodeja and Dr. I. Fernández

Departamento de Química Orgánica, Facultad de Química, Universidad Complutense, 28040 Madrid (Spain)

Fax: (+34)913944310

E-mail: israel@quim.ucm.es

[b] Prof. Dr. M. Solà

Institut de Química Computacional and Departament de Química, Universitat de Girona, Campus Montilivi, 17071 Girona, Spain.

[c] Prof. Dr. F. M. Bickelhaupt

Department of Theoretical Chemistry and Amsterdam Center for Multiscale Modeling (ACMM), VU University, De Boelelaan 1083, 1081 HV Amsterdam, and Institute for Molecules and Materials (IMM), Radboud University Nijmegen, Heyendaalseweg 135, NL-6525 AJ Nijmegen, The Netherlands.

\begin{abstract}
The Diels-Alder reactivity of different bowl-shaped polycyclic aromatic hydrocarbons (namely, corannulene, cyclopentacorannulene, diindenochrysene, hemifullerene, and circumtrindene) has been explored computationally within the Density Functional Theory framework. To this end, both the increase of the reactivity with the size of the buckybowl and the complete [6,6]regioselectivity in the process have been analyzed in detail using the activation strain model of reactivity in combination with the energy decomposition analysis method. Our results have been compared to the parent $\mathrm{C}_{60}$ fullerene, which also produces the corresponding $[6,6]$-cycloadduct exclusively. It is found that the behavior of the considered buckybowls resembles, in general, that of $\mathrm{C}_{60}$. Whereas the interaction energy between the deformed reactants along the reaction coordinate mainly controls the regioselectivity of the process, it is the interplay between the activation strain energy and the transition state interaction which governs the reactivity of the system.
\end{abstract}

Keywords: Buckybowls $\cdot$ fullerene $\cdot$ reactivity $\cdot$ DFT calculations $\cdot$ Diels-Alder 


\section{Introduction}

Bowl-shaped polycyclic aromatic hydrocarbons (PAHs), also known as buckybowls or fullerene fragments, are compounds which are characterized by curved $\pi$-systems composed of pyramidalized carbon atoms. ${ }^{[1-3]}$ Compounds such as corannulene, circumtrindene or diindenochrysene are representative members of this family of compounds. These species are also classified as open geodesic polyarenes because they do not comprise complete threedimensional polyhedra as $\mathrm{C}_{60}$ and higher fullerenes do (the latter classified as closed geodesic polyarenes) ${ }^{[2,3]}$ Whereas the chemistry of fullerenes is nowadays mature as reflected by the good number of fullerenes derivatives produced so far, ${ }^{[4]}$ even with high enantioselectivities ${ }^{[5]}$ the reactivity of buckybowls is comparatively underdeveloped. This is mainly due to the experimental difficulties associated with the synthesis of these molecules, which in many instances involves flash vacuum pyrolysis procedures and proceeds with low reaction yields. ${ }^{[6-9]}$

Despite that, bowl-shaped PAHs share an important topological feature with fullerenes as both families of compounds are constituted by fused five- and six-membered carbon rings. As a result, we can find two different types of $\mathrm{C}-\mathrm{C}$ bonds in these species: [6,6]-bonds, in which two six-membered rings are fused, and [5,6] bonds, corresponding to the ring junction between a five- and a six-membered ring. Both $\mathrm{C}_{60}$ and bowl-shaped fullerenes usually prefer [6,6]-bonds over $[5,6]$-bonds in their reactions, typically, addition and cycloaddition. ${ }^{[3,4]}$ For $\mathrm{C}_{60}$, the physical factors behind this extraordinary selectivity were not completely understood until our recent study ${ }^{[10]}$ using the Activation Strain Model (ASM) ${ }^{[11]}$ in combination with quantitative molecular orbital (MO) theory and the Energy Decomposition Analysis (EDA) ${ }^{[12,13]}$ method. We found that, for the [4+2]-cycloaddition reaction between $\mathrm{C}_{60}$ and cyclopentadiene, the major factor controlling the observed regioselectivity is the stronger interaction between the deformed reactants in the $[6,6]$ reaction pathway along the entire reaction coordinate as a consequence of a more effective $<\mathrm{HOMO}$ (cyclopentadiene)ILUMO(fullerene) $>$ molecular overlap involving the 
[6,6]-pyracylenic $\mathrm{C}-\mathrm{C}$ bond. This novel computational approach was also quite helpful to gain deeper insight into the differences of either reactivity or regioselectivity of higher fullerenes and endohedral fullerenes as compared to the parent $\mathrm{C}_{60} \cdot{ }^{[14,15]}$ The ASM or distortion/interaction model was also applied by Osuna and $\operatorname{Houk}^{[16 a]}$ in an exhaustive study of the Diels-Alder cycloaddition of s-cis-1,3-butadiene to the different bonds of, among others, corannulene, coronene, and two derivatives involving four additional five-membered rings added to the periphery of corannulene and coronene to increase their curvature. The authors convincingly proved that there is good correlation between activation barrier and activation strain for these systems. The $[5,6]$-attacks have a high activation strain and consequently higher barriers. The activation strain was related to the need to pyramidalize the attacked $\mathrm{C}$ atoms when going from reactants to transition state. Therefore, it is unclear yet whether the major factor governing the reactivity and the [6,6]-regioselectivity of buckybowls is the $\operatorname{strain}^{[16 a]}$ or the interaction energy ${ }^{[10]}$ Moreover, the similarity in reactivity and physicochemical properties of bowl-shaped PAHs with $\mathrm{C}_{60}$ strongly depends on the particular PAH under consideration. ${ }^{[3,16]}$ In general, a convergence to the $\mathrm{C}_{60}$ behavior is found when going from the smallest to the largest PAHs. ${ }^{[16 b, c]}$ Although issues such as the frontier-orbital energies or the degree of pyramidalization of the trigonal carbon atoms (quantitatively expressed by the angle between the p-orbital axis vectors, i.e. the POAV index $)^{[17]}$ have been traditionally used to rationalize the reactivity of PAHs ${ }^{[3]}$ the physical factors controlling the reactivity of this family of compounds are so far not completely understood either. 


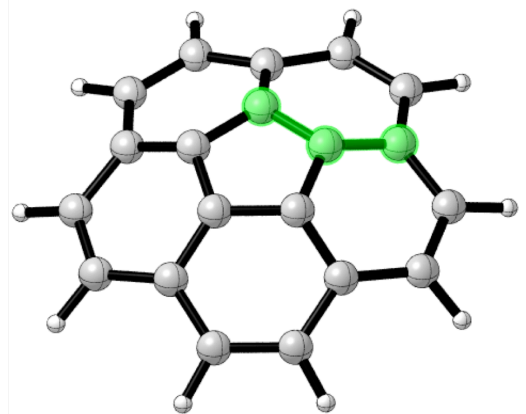

1, corannulene

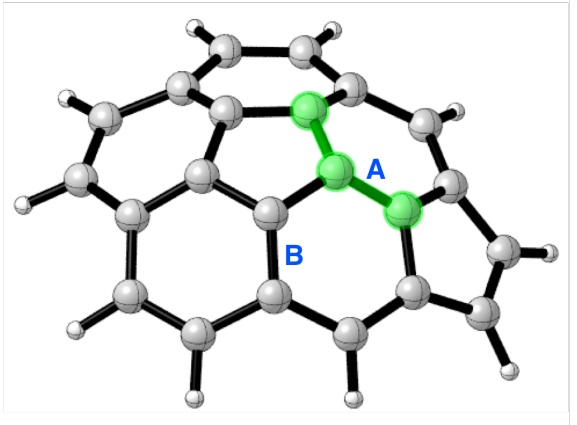

2, cyclopentacorannulene

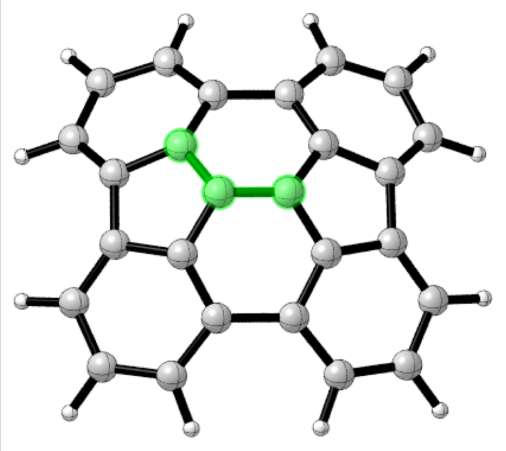

3, diindenochrysene

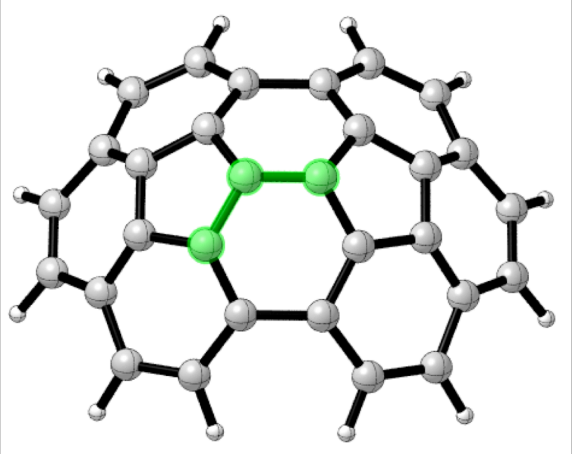

4, hemifullerene

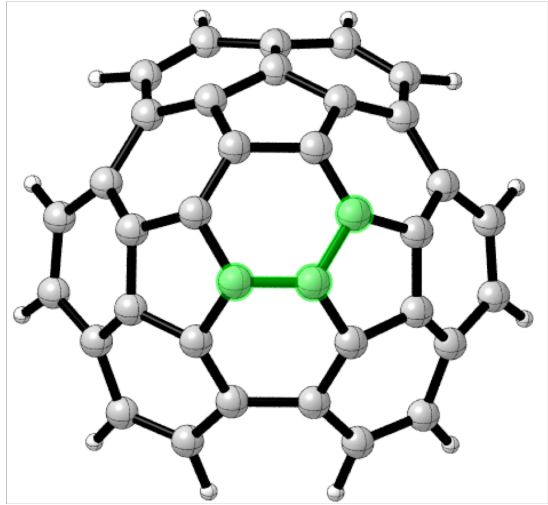

5, circumtrindene

Chart 1. Bowl-shaped polycyclic aromatic hydrocarbons considered in this study. [6,6]and $[5,6]$ studied bonds are highlighted.

For these reasons, herein we decided to apply the combination of the ASM and EDA methods to bowl-shaped PAHs in order to gain a quantitative understanding of those factors governing both the reactivity and regioselectivity of these species. To this end, we have selected the [4+2]-cycloaddition reaction between cyclopentadiene and the PAHs 1-5 depicted in Chart 1. All of these compounds have been already synthesized.$^{[3,7]}$ We have studied the bonds that are marked in Chart 1. Although it is known that the bonds in the periphery are, in general, more reactive that those in the center ${ }^{[16 a, 18]}$ we have preferred to analyze the reactivity of the $[5,6]$ and $[6,6]$ bonds in the center of the PAHs because they behave more similarly to those of $\mathrm{C}_{60}$. These processes shall be therefore compared with the analogous reaction involving $\mathrm{C}_{60}$, which was previously studied by us, ${ }^{[10]}$ and analyzed by means of the combined ASM/EDA methodologies. 


\section{Theoretical Methods}

\section{Computational Details}

Geometry optimizations of the molecules were performed without symmetry constraints using the Gaussian03 $3^{[19]}$ optimizer together with Turbomole $6.6^{[20]}$ energies and gradients at the $\mathrm{BP}^{2} 6^{[21]} / \mathrm{def} 2-\mathrm{SVP}^{[22]}$ level of theory using the D3 dispersion correction suggested by Grimme et al. ${ }^{[23]}$ and the resolution-of-identity (RI) approximation. ${ }^{[24]}$ This level is denoted RI-BP86D3/def2-SVP and has been selected because it provides very good results for cycloaddition reactions involving fullerenes. ${ }^{[10-12]}$ The inclusion of dispersion corrections was found to be essential in the study of the chemical reactivity of fullerenes. ${ }^{[10,14,15,25]}$ Reactants and cycloadducts were characterized by frequency calculations, and have positive definite Hessian matrices. Transition structures (TS's) show only one negative eigenvalue in their diagonalized force constant matrices, and their associated eigenvectors were confirmed to correspond to the motion along the reaction coordinate under consideration using the Intrinsic Reaction Coordinate (IRC) method. ${ }^{[2]}$ Single-point energy refinements were carried out at the same DFT level using the triple- $\zeta$-quality def2-TZVPP basis sets. ${ }^{[22]}$ This level is therefore denoted BP86-D3/def2TZVPP//RI-BP86-D3/def2-SVP.

\section{Activation Strain Analyses of Reaction Profiles}

The activation strain model, also known as distortion/interaction model, is a fragment approach to understanding chemical reactions, in which the height of reaction barriers is described and understood in terms of the original reactants. ${ }^{[11,27]}$ Indeed, this method has successfully contributed to our current understanding of different types of processes, such as $\mathrm{S}_{\mathrm{N}} 2$ and E2 reactions, ${ }^{[28]}$ pericyclic reactions,${ }^{[29]}$ and metal-promoted transformations. ${ }^{[30]}$ The Activation Strain model is a systematic extension of the fragment approach from equilibrium structures to transition states as well as non-stationary points, e.g., points along a reaction coordinate. Thus, the potential energy surface $\Delta E(\zeta)$ is decomposed, along the reaction 
coordinate $\zeta$, into the strain $\Delta E_{\text {strain }}(\zeta)$ associated with deforming the individual reactants plus the actual interaction $\Delta E_{\text {int }}(\zeta)$ between the deformed reactants:

$$
\Delta E(\zeta)=\Delta E_{\text {strain }}(\zeta)+\Delta E_{\text {int }}(\zeta)
$$

Here, the reaction coordinate is defined as the projection of the IRC on the forming $C \cdots \mathrm{C}$ distance between the carbon atom of the buckybowl and the carbon atom of cyclopentadiene. This reaction coordinate $\zeta$ undergoes a well-defined change in the course of the reaction from the initially formed reactant complexes to the equilibrium $\mathrm{C} \cdots \mathrm{C}$ distance in the corresponding transition states. Since most located transition states are concerted and asynchronous, we have considered in all cases the shortest $\mathrm{C} \cdots \mathrm{C}$ distance as the reaction coordinate.

The strain $\Delta E_{\text {strain }}(\zeta)$ is determined by the rigidity of the reactants and by the extent to which groups must reorganize in a particular reaction mechanism, whereas the interaction $\Delta E_{\text {int }}(\zeta)$ between the reactants depends on their electronic structure and on how they are mutually oriented as they approach each other. It is the interplay between $\Delta E_{\text {strain }}(\zeta)$ and $\Delta E_{\text {int }}(\zeta)$ that determines if and at which point along $\zeta$ a barrier arises, namely, at the point where $\mathrm{d} \Delta E_{\text {strain }}(\zeta) / \mathrm{d} \zeta=-\mathrm{d} \Delta E_{\text {int }}(\zeta) / \mathrm{d} \zeta$. The activation energy of a reaction $\Delta E^{\ddagger}=\Delta E\left(\zeta^{\mathrm{TS}}\right)$ consists of the activation strain $\Delta E_{\text {strain }}^{\ddagger}=\Delta E_{\text {strain }}\left(\zeta^{\mathrm{TS}}\right)$ plus the TS interaction $\Delta E_{\text {int }}^{\ddagger}=\Delta E_{\text {int }}\left(\zeta^{\mathrm{TS}}\right)$,

$$
\Delta E^{\ddagger}=\Delta E_{\text {strain }}^{\ddagger}+\Delta E_{\text {int }}^{\ddagger}
$$

\section{Energy Decomposition Analysis}

The interaction $\Delta E_{\text {int }}(\zeta)$ between the strained reactants can be further analyzed in the conceptual framework provided by the Kohn-Sham molecular orbital (KS-MO) model. ${ }^{[12,13]}$ To this end, this term is further decomposed into the following physically meaningful terms:

$$
\Delta E_{\text {int }}(\zeta)=\Delta V_{\text {elstat }}+\Delta E_{\text {Pauli }}+\Delta E_{\text {orb }}+\Delta E_{\text {disp }}
$$


The term $\Delta V_{\text {elstat }}$ corresponds to the classical electrostatic interaction between the unperturbed charge distributions of the deformed reactants and is usually attractive. The Pauli repulsion $\Delta E_{\text {Pauli }}$ comprises the destabilizing interactions between occupied orbitals and is responsible for any steric repulsion. The orbital interaction $\Delta E_{\text {orb }}$ accounts for charge transfer (interaction between occupied orbitals on one moiety with unoccupied orbitals on the other, including HOMO-LUMO interactions) and polarization (empty-occupied orbital mixing on one fragment due to the presence of another fragment). Finally, the $\Delta E_{\text {disp }}$ term takes into account the interactions which are due to dispersion forces.

The program package ADF 2013.01 $1^{[31]}$ was used for the EDA calculations at the BP86-D3 level, in conjunction with a triple- $\zeta$-quality basis set using uncontracted Slater-type orbitals (STOs) augmented by two sets of polarization functions with a frozen-core approximation for the core electrons. ${ }^{[32]}$ Auxiliary sets of s, p, d, f, and g STOs were used to fit the molecular densities and to represent the Coulomb and exchange potentials accurately in each SCF cycle. ${ }^{[33]}$ Scalar relativistic effects were incorporated by applying the zeroth-order regular approximation (ZORA). ${ }^{[34]}$ This level of theory is denoted ZORA-BP86-D3/TZ2P//RI-BP86-D3/def2-SVP.

\section{Results and Discussion}

The computed reaction profiles depicted in Figure 1 resemble that computed for the parent $\mathrm{C}_{60}$ fullerene. ${ }^{[10]}$ Thus, the reactions begin from the corresponding reactant complexes (RC), which are ca. $6 \mathrm{kcal} / \mathrm{mol}$ more stable than the separate reactants, and then proceed concertedly through the respective $[6,6]$ - or $[5,6]$-transition states (TS) to the final cycloadducts. Furthermore, in all cases the transformation is completely regioselective leading to the exclusive formation of the $[6,6]$ cycloadduct, which is kinetically and also thermodynamically favored (with the exception of corannulene) over the [5,6]-isomer. Interestingly, a closer examination of the fully optimized geometries of the corresponding transition states (Figure 2) reveals that, first, all transition states are concerted, second, in most cases all of them are asynchronous with the 
forming $C \cdots C$ closest to the periphery being shorter than that of the center, ${ }^{[16 a]}$ and, third, with the notable exception of TS1-[6,6], the $[6,6]$-saddle points are clearly more synchronous and are reached earlier than their $[5,6]$-counterparts, as measured by the shortest of the two $\mathrm{C} \cdots \mathrm{C}$ bonds that are formed in the reaction. The latter finding also resembles the behavior of $\mathrm{C}_{60}$, in which the corresponding TS-[6,6] is reached earlier than TS-[5,6] $(C \cdots C=2.226 \AA$ vs $C \cdots C=2.103 \AA$, respectively). ${ }^{[10]}$
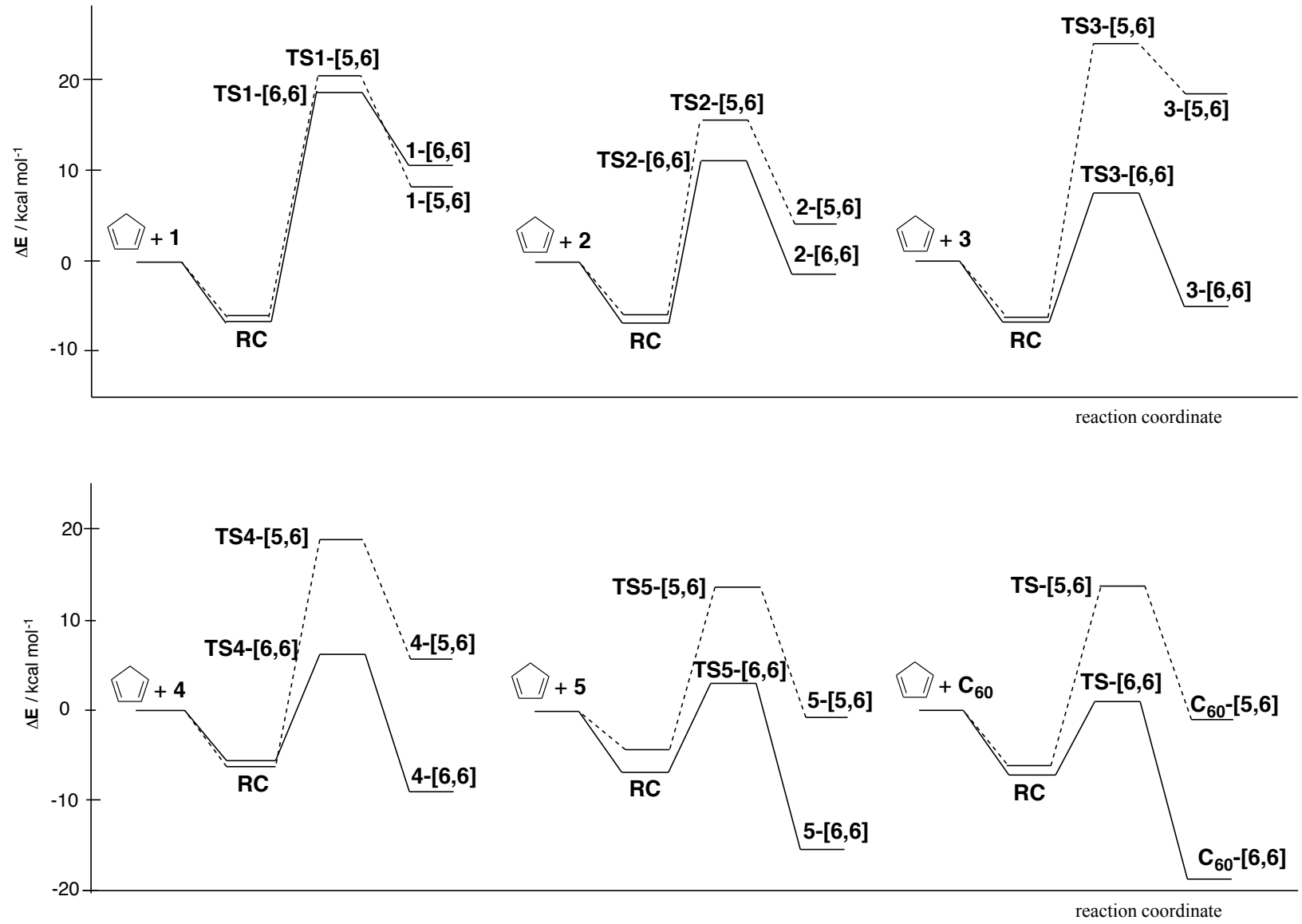

Figure 1. Computed reaction profiles for the Diels-Alder cycloaddition reactions between cyclopentadiene and buckybowls $\mathbf{1 - 5}$ and $\mathrm{C}_{60}$. All data have been computed at the BP86-D3/def2TZVPP//RI-BP86-D3/def2-SVP level. 


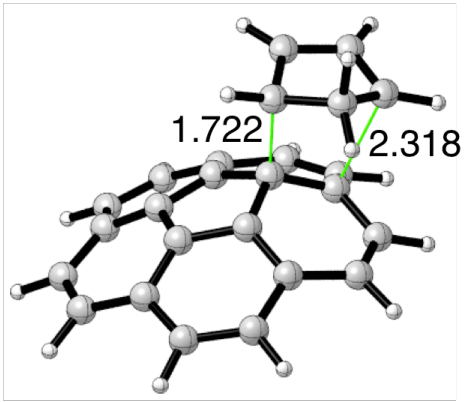

TS1-[6,6]

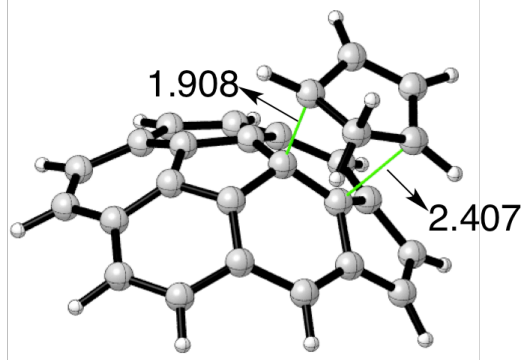

TS2-[6,6]

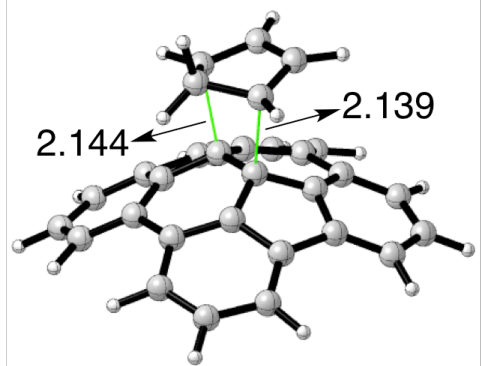

TS3-[6,6]

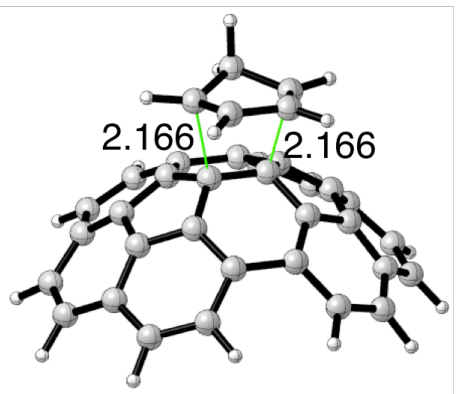

TS4-[6,6]

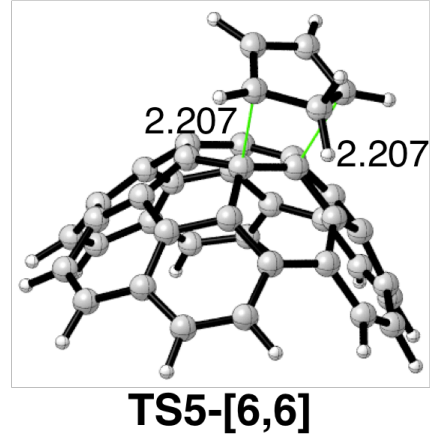

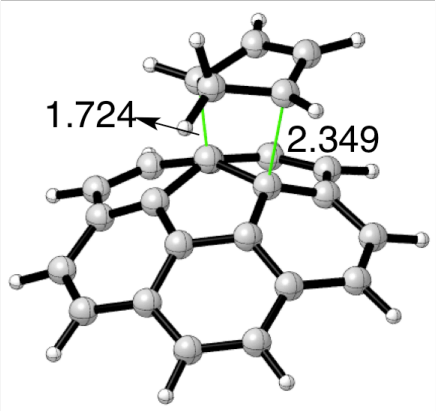

TS1-[5,6]

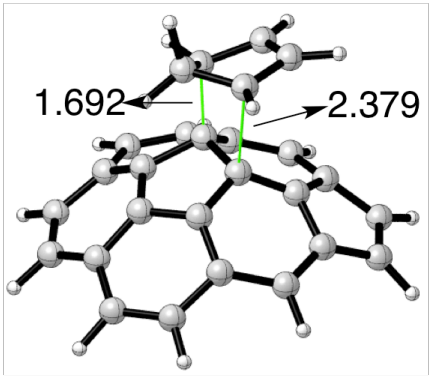

TS2-[5,6]

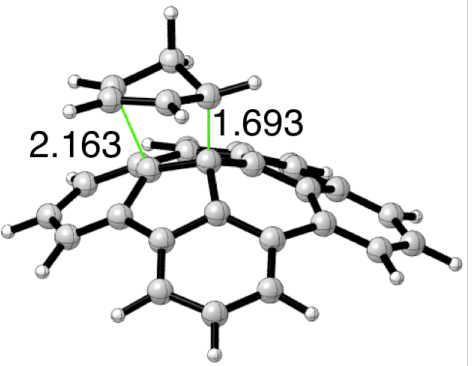

TS3-[5,6]

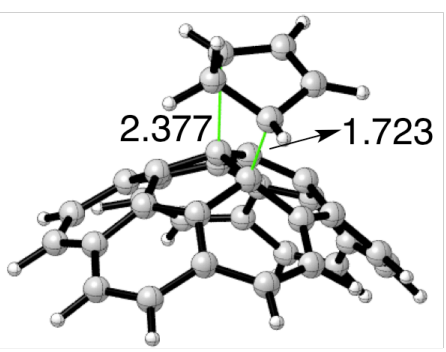

TS4-[5,6]

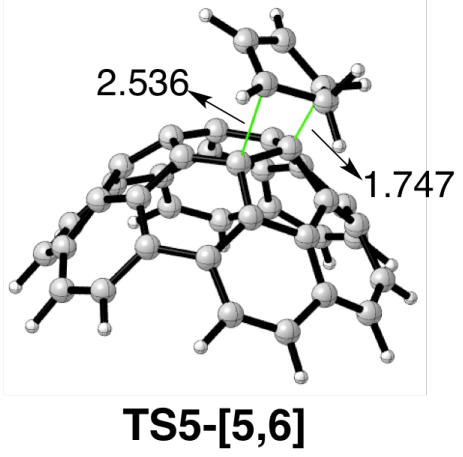

Figure 2. Fully optimized geometries (RI-BP86-D3/def2-SVP level) of the transition states involved in the Diels-Alder cycloaddition reactions between cyclopentadiene and buckybowls 15. Bond distances are given in angstroms. 
Despite that, significant differences in the reactivity of the considered PAHs are observed. As shown in Table 1, the favored [6,6]-pathway occurs with a lower activation barrier and becomes more exothermic as the size of the buckybowl increases. Interestingly, starting from corannulene there is a smooth convergence to the $\mathrm{C}_{60}$ energy barrier and reaction energy for the $[6,6]$ attack when the size of the buckybowl is increased. Indeed, the kinetics and thermodynamics of the Diels-Alder reaction to circumtrindene is almost the same as that of $\mathrm{C}_{60}$. Moreover, there is a clear correlation between the computed activation $\left(\Delta E^{\ddagger}\right)$ and reaction energies $\left(\Delta E_{\mathrm{R}}\right)$ for the favored [6,6]-pathway (linear relationship with correlation coefficient of 0.996, and standard deviation of 0.78 , see Figure 3). Interestingly, the slope of the linear relationship is really close to 0.5 , which indicates that the considered Diels-Alder reactions between cyclopentadiene and buckybowls and $\mathrm{C}_{60}$ follows the empirical relationship $\Delta E^{\star}=\Delta E_{0}^{*}$ $+1 / 2 \Delta E_{\mathrm{R}}$, given by Brønsted, Dimroth, Marcus, Bell-Evans-Polanyi (also known as the Bema Hapothle relationship) ${ }^{[35]}$ A very similar result was found by Osuna and Houk for the DielsAlder reactions between s-cis-1,3-butadiene and corannulene, coronene, and two of their derivatives. ${ }^{[16 a]}$ This relationship was also found for both the hydrogenation and Diels-Alder reactions of related planar and branched hydrocarbons,${ }^{[36]}$ and even of endohedral fullerenes, ${ }^{[37]}$ therefore indicating reactivity likeness of these species. 
Table 1. Computed energies (in kcal/mol, BP86-D3/def2-TZVPP//RI-BP86-D3/def2-SVP level) for the Diels-Alder cycloaddition reactions between cyclopentadiene and buckybowls 1-5 and $\mathrm{C}_{60}$.

\begin{tabular}{|c|c|c|c|c|}
\hline Compound & pathway & $\Delta \mathbf{E}_{\mathrm{RC}}^{[\mathrm{a}]}$ & $\Delta E^{\ddagger[b]}$ & $\Delta \mathbf{E}_{\mathbf{R}}^{[\mathbf{c}]}$ \\
\hline 1 & {$[6,6]$} & -5.7 & 24.2 & 10.2 \\
\hline (corannulene) & {$[5,6]$} & -5.6 & 26.3 & 8.8 \\
\hline 2 & {$[6,6]^{[\mathrm{d}]}$} & -5.9 & 17.5 & -1.0 \\
\hline (cyclopentacorannulene) & {$[5,6]$} & -5.2 & 21.0 & 4.2 \\
\hline 3 & {$[6,6]$} & -6.9 & 14.5 & -5.5 \\
\hline (diindenochrysene) & {$[5,6]$} & -6.5 & 30.8 & 18.6 \\
\hline 4 & {$[6,6]$} & -5.6 & 12.3 & -9.6 \\
\hline (hemifullerene) & {$[5,6]$} & -5.8 & 24.5 & 6.4 \\
\hline 5 & {$[6,6]$} & -5.7 & 9.6 & -15.2 \\
\hline (circumtrindene) & {$[5,6]$} & -4.7 & 19.1 & -0.3 \\
\hline $\mathrm{C}_{60}$ & {$[6,6]$} & -7.4 & 8.2 & -19.1 \\
\hline (fullerene) & {$[5,6]$} & -6.3 & 21.0 & -1.6 \\
\hline
\end{tabular}

[a] Reactant complex (RC) energy: $\Delta E_{\mathrm{RC}}=E_{\mathrm{RC}}-E$ (buckybowl) $-E$ (cyclopentadiene). [b] Activation energy: $\Delta E^{\ddagger}=\mathrm{E}(\mathbf{T S})-\mathrm{E}(\mathbf{R C})$. [c] Reaction energy: $\Delta E_{\mathrm{R}}=E$ (cycloadduct) $E$ (buckybowl) - E(cyclopentadiene). [d] Data computed for [6,6]-bond A (see Chart 1). The corresponding TS for the cycloaddition involving [6,6]-bond B lies ca. $1.0 \mathrm{kcal} / \mathrm{mol}$ above TS2[6,6] (bond A).

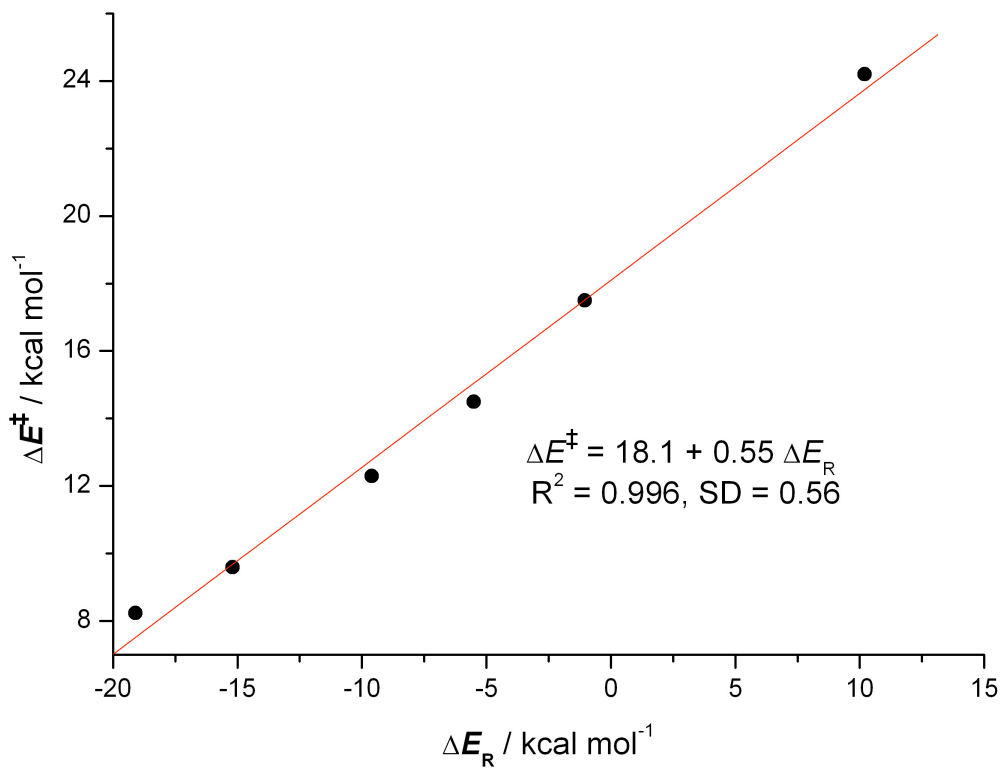


Figure 3. Plot of the reaction energies $\left(\Delta E_{\mathrm{R}}\right)$ vs energy barriers $\left(\Delta E^{\ddagger}\right)$ for the Diels-Alder cycloaddition reactions between cyclopentadiene and the [6,6]-bonds of buckybowls $\mathbf{1 - 5}$ and $\mathrm{C}_{60}$. Energy values were computed at the BP86-D3/def2-TZVPP//RI-BP86-D3/def2-SVP level.

Deeper insight into the physical factors controlling the barrier heights of the $[6,6]-$ and $[5,6]$-cycloaddition reactions can be gained by using the activation strain model. Figure 4 shows the computed activation strain diagrams (ASD) from the initial stages of the processes to the corresponding transition states. As readily seen in Figures 4a-e, all systems exhibit quite similar ASD. Thus, in all cases the interaction energy between the deformed reactants, measured by $\Delta E_{\text {int }}$, remains constant or becomes slightly destabilizing at the beginning of the reaction. However, it inverts at a certain point along the reaction coordinate and becomes more and more stabilized as one approaches the transition state region. This behavior resembles that found not only for related cycloaddition reactions ${ }^{[29 b, g]}$ but also for other pericyclic reactions such as doublegroup transfer reactions, ${ }^{[29 a]}$ Alder-ene reactions ${ }^{[29 c]}$ or ene-ene-yne cyclizations ${ }^{[29 \mathrm{~h}]}$ and is different for other processes like $\mathrm{S}_{\mathrm{N}} 2$ reactions ${ }^{[28]}$ where the $\Delta E_{\text {int }}$ term is stabilizing along the entire reaction coordinate. Despite that, the stabilization provided by the interaction term cannot compensate the strong destabilizing effect of the deformation energy required to adopt the transition state geometry $\left(\Delta E_{\text {strain }}\right)$, which in turn becomes the major factor controlling the activation barriers of the [4+2]-cycloaddition reactions involving these geodesic polyarenes. 
a)

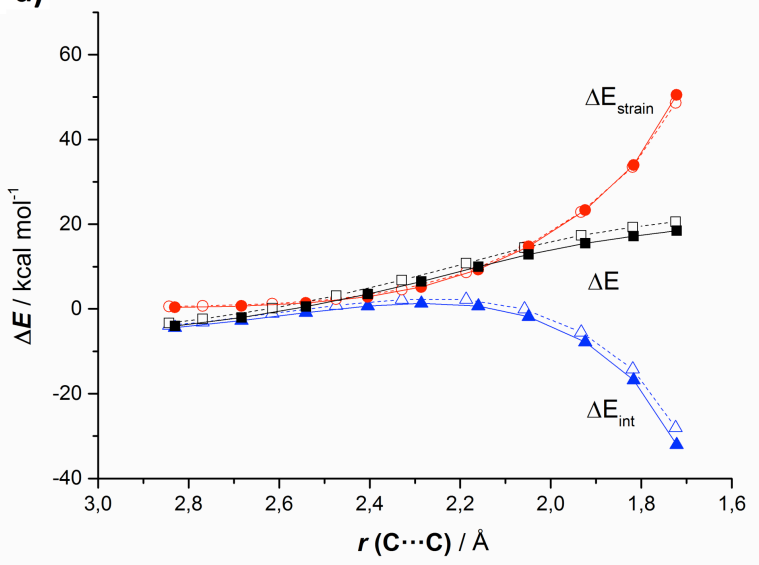

c)

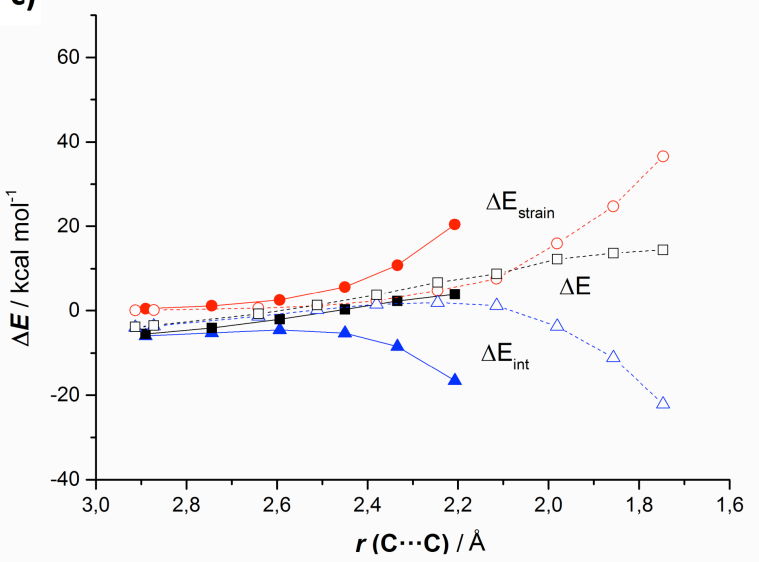

e)

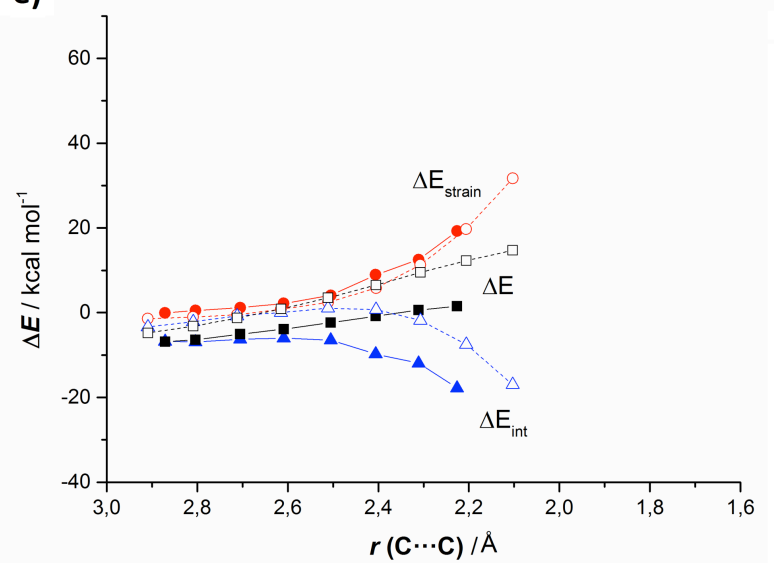

b)

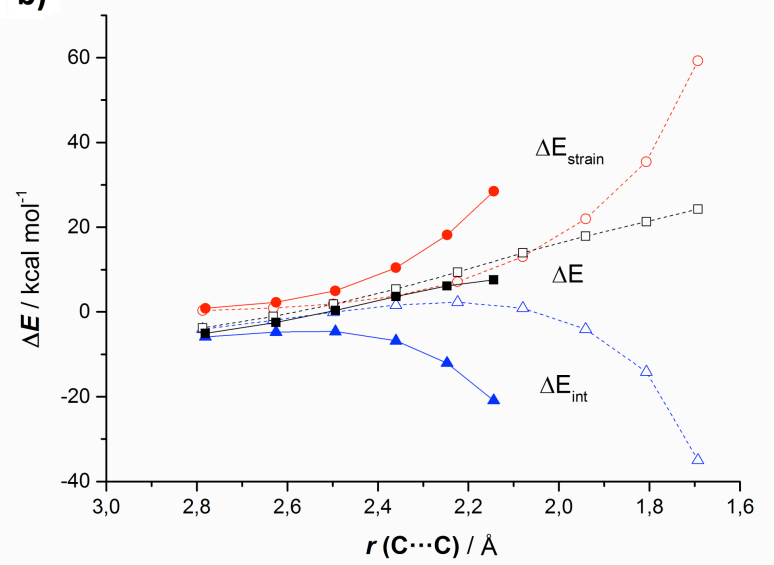

d)

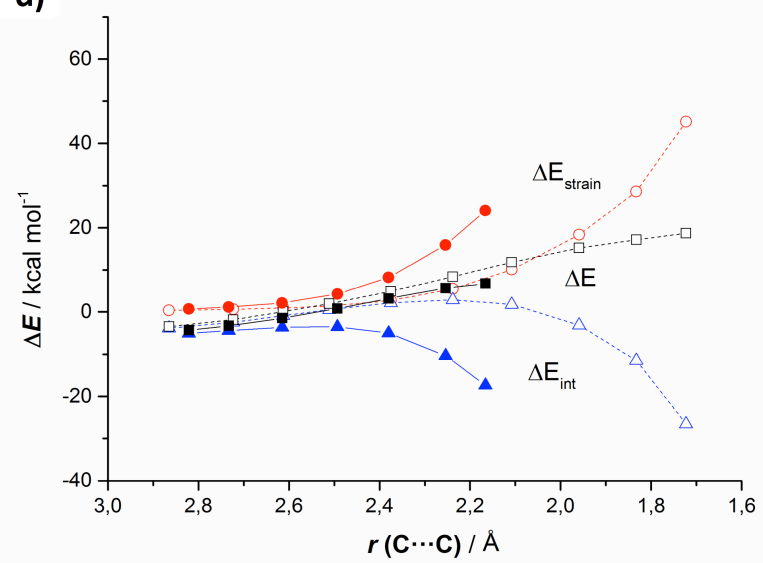

Figure 4. Activation-strain diagrams of the [4+2]-cycloaddition reaction between cyclopentadiene and corannulene 1 (a), diindenochrysene 3 (b), hemifullerene 4 (c), circumtrindene $5(\mathrm{~d})$, and $\mathrm{C}_{60}$ (e) along the reaction coordinate projected onto the forming $\mathrm{C} \cdots \mathrm{C}$ bond distance. Solid lines refer to the [6,6]-pathway whereas dotted lines to the [5,6]-pathway. All data have been computed at the BP86-D3/def2-TZVPP//RI-BP86-D3/def2-SVP level. 
The ASD depicted in Figure 4 clearly show the reasons for the computed (and experimentally observed) complete [6,6]-regioselectivity. Similar to the parent fullerene $\mathrm{C}_{60}$ (see also Figure $4 \mathrm{e}),{ }^{[10]}$ the interaction energy between the deformed reactants favors, i.e., is more stabilizing for, the [6,6]-pathway (solid lines) along the entire reaction coordinate as compared to the [5,6]-pathway (dotted lines). This stronger interaction in the [6,6]-path can even compensate the less destabilizing strain energy, associated with deforming the individual reactants along the reaction path, computed for the [5,6]-pathway. As a result, the $[6,6]$-cycloadduct is kinetically favored in all cases. Indeed, a barrier energy difference $\left(\Delta \Delta E^{\ddagger}\right)$ of more than $10 \mathrm{kcal} / \mathrm{mol}$ was computed for all the species considered with the notable exception of the process involving corannulene (1), where the computed difference between [5,6]- and [6,6]-pathways was much lower $\left(\Delta \Delta E^{*}=2.1 \mathrm{kcal} / \mathrm{mol}\right.$, see Table 1$)$. As commented above, this is mainly due to the much later nature of the transition state TS1-[6,6], which instead of resembling the other TS-[6,6] of the series, is quite similar to the late and asynchronous TS-[5,6] (see Figure 2). Despite that, even in this system, it becomes clear that the stronger interaction for the $[6,6]$-pathway along the entire reaction coordinate, and especially at the transition state region, is the major factor controlling the regioselectivity of the cycloaddition reaction (in the particular case of $\mathbf{1}$, the difference in the $\Delta E_{\text {strain }}$ for both reaction pathways is negligible).

Interestingly, the ASM is also quite helpful to understand the computed trend of reactivity in these systems, i.e., the [4+2]-reactivity increases with the size of the buckybowl. At this point, we want to point out that the degree of pyramidalization should be used with caution to rationalize the reactivity of these PAHs. For instance, the experimental (X-ray crystallography) derived average POAV angles follow the trend: $8.3^{\circ}(\mathbf{1}),{ }^{[38]} 9.6(\mathbf{2}),{ }^{[7]} 9.0^{\circ}(\mathbf{3}),{ }^{[39]} 10.7^{\circ}(\mathbf{4}),{ }^{[40]} 12.1^{\circ}$ $(\mathbf{5})^{[41]}$ and $11.6^{\circ}\left(\mathrm{C}_{60}\right),{ }^{[3]}$ which indicates that cyclopentacorannulene $\mathbf{2}$ and circumtrindene $\mathbf{5}$ should be more reactive than diindenochrysene 3 and $\mathrm{C}_{60}$, respectively (our calculations indicate that $\mathbf{3}$ and $\mathrm{C}_{60}$ are more reactive than $\mathbf{2}$ and $\mathbf{5}$, respectively, see Table 1). As graphically shown in Figure 5 , both the activation strain $\left(\Delta E_{\text {strain }}{ }^{\ddagger}\right)$ and the TS interaction $\left(\Delta E_{\text {int }}{ }^{\dagger}\right)$ correlate with the 
computed activation barriers (all energies were computed relative to the corresponding reactant complexes, RC). Although the linear relationship is better for the former activation term $\left(\mathrm{R}^{2}=\right.$ $0.97, \mathrm{SD}=3.37)$, the TS interaction also contributes significantly to the control of the process $\left(\mathrm{R}^{2}\right.$ $=0.86, \mathrm{SD}=3.38)$. This finding contrasts to related [4+2]-cycloaddition reactions involving cycloalkenones $^{[42]}$ or endohedral fullerenes of the type $\mathrm{Ng}_{2} @ \mathrm{C}_{60}\left(\mathrm{Ng}=\right.$ noble gas ${ }^{[14]}$ where the TS interaction between the deformed reactants was found to remain nearly constant with respect to the size of the dienophile. Therefore, not only the deformation required to adopt the corresponding transition state geometry but also the interaction between the deformed reactants are responsible for the observed trend of [4+2]-reactivity of buckybowls.

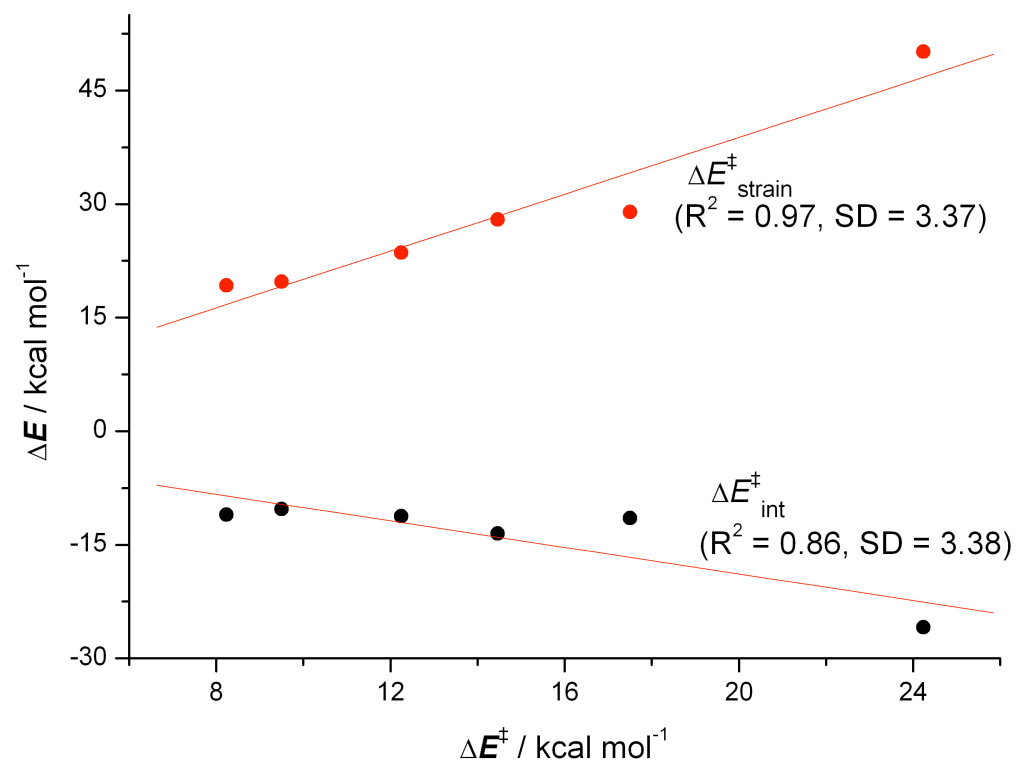

Figure 5. Plot of the activation strain energies $\left(\Delta E_{\text {strain }}^{\ddagger}\right.$ and $\left.\Delta E_{\text {int }}^{\ddagger}\right)$ vs barrier energies $\left(\Delta E^{\ddagger}\right)$ for the Diels-Alder cycloaddition reactions between cyclopentadiene and the [6,6]-bonds of buckybowls 1-5 and $\mathrm{C}_{60} . \Delta E^{\ddagger}=E(\mathbf{T S})-E(\mathbf{R C}) . \Delta E_{\text {int }}^{\ddagger}=E_{\text {int }}(\mathbf{T S})-E_{\text {int }}(\mathbf{R C}) . \Delta E_{\text {strain }}^{\ddagger}=E_{\text {strain }}(\mathbf{T S})$ - $E_{\text {strain }}(\mathbf{R C})$. All data were computed at the BP86-D3/def2-TZVPP//RI-BP86-D3/def2-SVP level.

As the interaction energy between the deformed reactants greatly contributes to the reactivity and regioselectivity of the PAHs, we then used the Energy Decomposition Analysis (EDA) method to further analyze the different contributors to the $\Delta E_{\text {int }}$ term. Figure 6a-e gathers 
the EDA terms along the reaction coordinate again from the beginning of the process to the TS geometries for the $[6,6]$ as well as for $[5,6]$-reaction pathways. In all cases, it becomes clear that whereas dispersion forces are significant at the initial stages of the transformation, the $\Delta E_{\text {disp }}$ term remains practically constant along the reaction coordinate and therefore is not decisive in favoring the [6,6]-pathway with respect to the [5,6]-path. At variance, both the orbital and electrostatic terms, which are weak at the beginning of the process, become the major contributors to the total attractions in the TS region (in approximately the same extent). Both terms are clearly more stabilizing in the [6,6]-pathway along the entire reaction coordinate, which is translated into the computed stronger interaction for this reaction path. Although the behavior of the EDA terms for the process involving $\mathrm{C}_{60}$ is quite similar (see also Figure 6e), ${ }^{[10]}$ there is a subtle difference between this particular system and buckybowls. Indeed, when comparing the destabilizing Pauli repulsion term (measured by the $\Delta E_{\text {Pauli }}$ ) for both pathways, we realize that this term is slightly less destabilizing for the [6,6]-pathways involving $\mathrm{C}_{60}$. Differently, $\Delta E_{\text {Pauli }}$ becomes lower for the [5,6]-pathways involving the open geodesic polyarenes (with the exception of corannulene, where the $\Delta E_{\text {Pauli }}$ term is practically identical for both pathways). Despite this subtle difference which has no appreciable impact on the regioselectivity of the process, it can be safely concluded that the stronger interaction between the deformed reactants, which is responsible for the exclusive formation of $[6,6]$-cycloadducts, finds its origin in the higher orbital and electrostatic interactions between the reactants along the $[6,6]$-pathway as compared to the corresponding [5,6]-path. 
a)

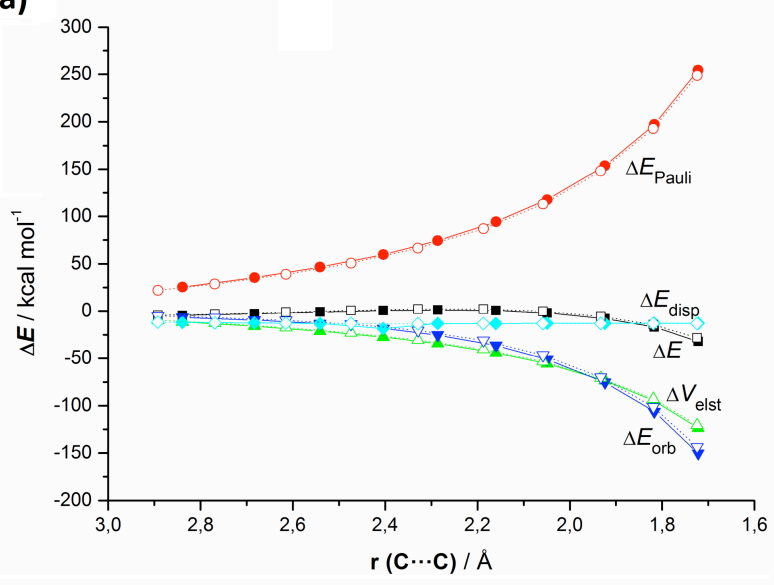

c)

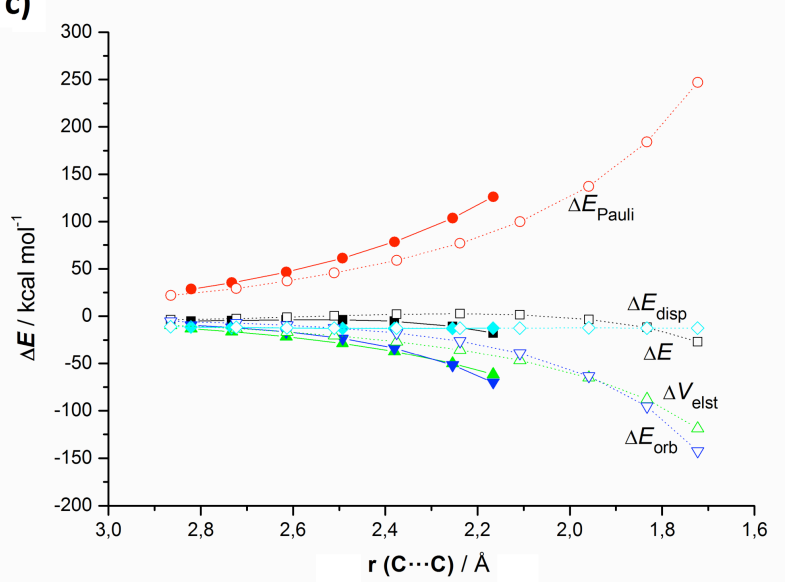

e)

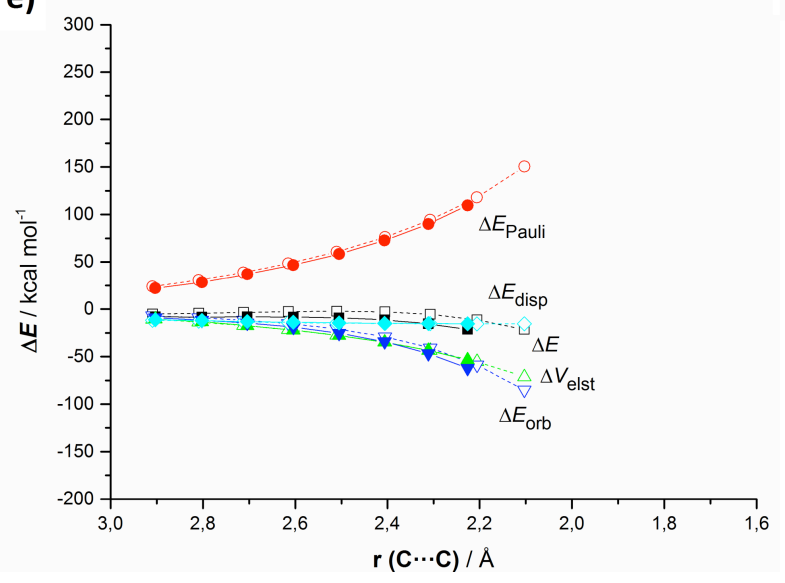

b)

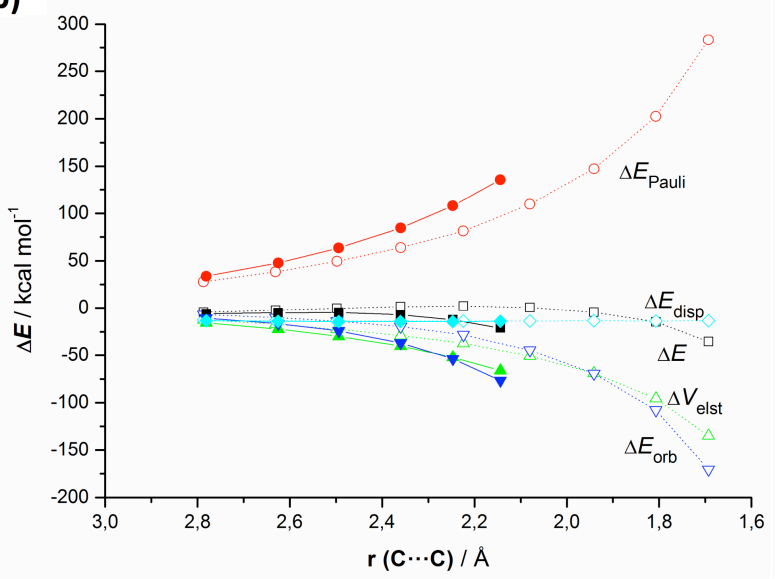

d)

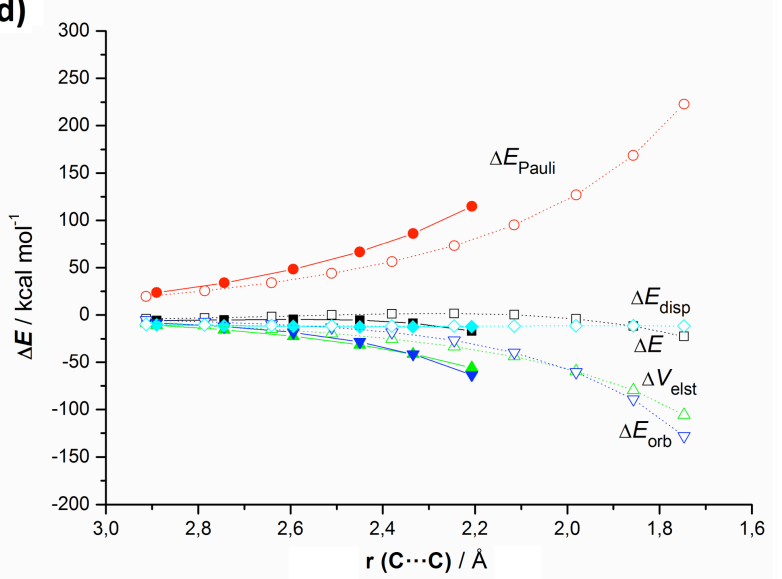

Figure 6. Decomposition of the interaction energy for the [4+2]-cycloaddition reactions between cyclopentadiene and corannulene (a), diindenochrysene (b), hemifullerene (c), circumtrindene (d), and $\mathrm{C}_{60}$ (e) along the reaction coordinate projected onto the forming $\mathrm{C} \cdots \mathrm{C}$ bond distance. Solid lines refer to the [6,6]-pathway whereas dotted lines to the [5,6]-pathway. All data have been computed at the ZORA-BP86-D3/TZ2P+//RI-BP86-D3/def2-SVP level. 
Previously, we have shown that the stronger orbital interactions in the $[6,6]$-pathway involving $\mathrm{C}_{60}$ or endohedral fullerenes are strongly related to the orbital overlap $(S)$ involving the reactive frontier molecular orbitals. ${ }^{[10,14,15]} \mathrm{We}$ then were curious to confirm whether such relationship also holds in the buckybowls considered in the present study. Figures $7 \mathrm{a}$ and $7 \mathrm{~b}$ shows the computed $<\mathrm{HOMO}$ (cyclopentadiene)ILUMO(buckybowl) $>$ molecular overlaps for the reactions involving corannulene (1) and hemifullerene (4) along the $[6,6]$ - and $[5,6]$-pathways, respectively. In both cases, the computed overlap is higher for the [6,6]-path along the entire reaction coordinate, which is consistent with the stronger orbital interactions computed for this favored pathway. Interestingly, the $[6,6] /[5,6]$ overlap difference is clearly much lower for the process involving corannulene as compared to hemifullerene. As a result, the computed $[6,6] /[5,6]$ orbital interaction difference is also much lower which in turn is translated into a lower interaction energy difference (see Figure 3 ) and finally, into a lower $[6,6] /[5,6]$ activation barrier difference (see Table 1). Nevertheless, it is confirmed that the trend in the computed $<\mathrm{HOMO}$ (cyclopentadiene)|LUMO(buckybowl) $>$ overlap indicates that, similar to $\mathrm{C}_{60}$, the $[6,6]-$ pathway benefits in general from a much better HOMO-LUMO overlap from the initial reactant complex to the corresponding TS in the considered PAHs. This can be ascribed simply to the shape of the LUMO of the PAH-dienophiles, which exhibits larger amplitudes and the appropriate $\pi^{*}$ character on [6,6]-bonds but not on [5,6]-bonds (Figure 8).
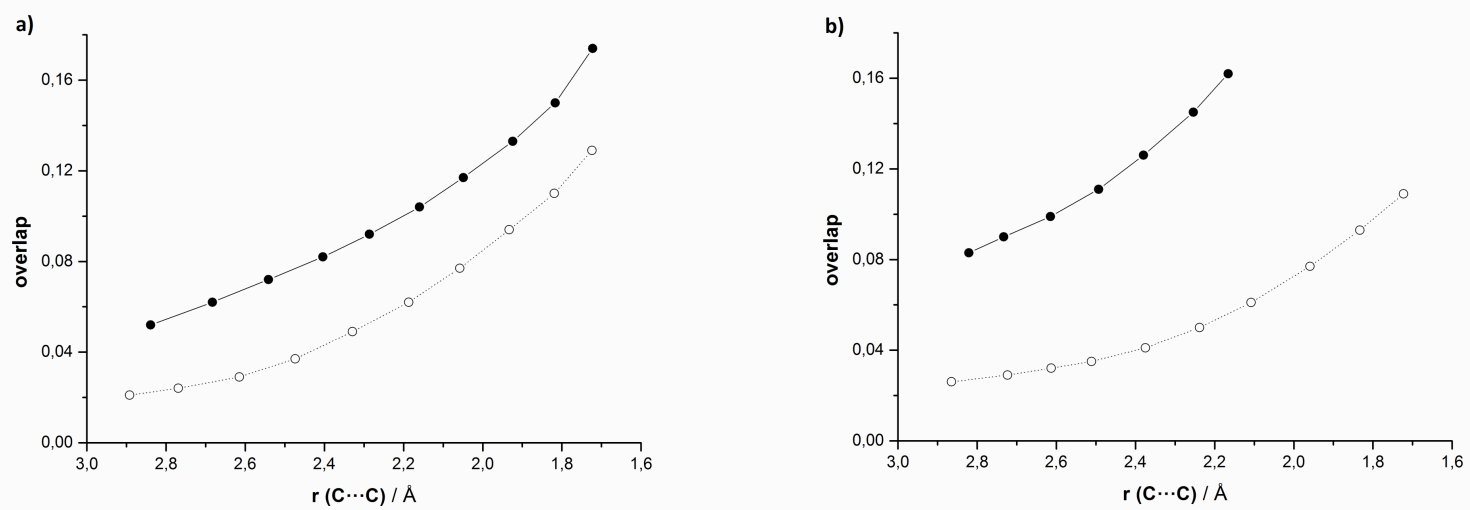
Figure 7. (a) Computed <HOMO(cyclopentadiene)|LUMO(buckybowl)> overlap for the [4+2]cycloaddition reaction between cyclopentadiene and corannulene (a) and hemifullerene (b). Solid lines refer to the [6,6]-pathway whereas dotted lines to the [5,6]-pathway. All data have been computed at the ZORA-BP86-D3/TZ2P+//RI-BP86-D3/def2-SVP level.

Moreover, the data gathered in Figure 8 clearly indicate that one should be extremely cautious when correlating reactivity (i.e. activation barriers) directly with the computed HOMO(diene)-LUMO(buckybowl) gap. For instance, the [4+2]-cycloaddition involving hemifullerene 4 proceeds with a lower activation barrier $\left(\Delta E^{\ddagger}=12.3 \mathrm{kcal} / \mathrm{mol}\right)$ than diindenochrysene $3\left(\Delta E^{\ddagger}=14.5 \mathrm{kcal} / \mathrm{mol}\right)$ despite the former system exhibits a larger HOMO(diene)-LUMO(dienophile) gap (2.38 eV vs $2.29 \mathrm{eV}$, see Figure 8). ${ }^{[42]}$ This finding confirms, once again, that qualitative FMO arguments can not be based only on orbital-energy gaps and that overlap must be taken into account. ${ }^{[43-45]}$

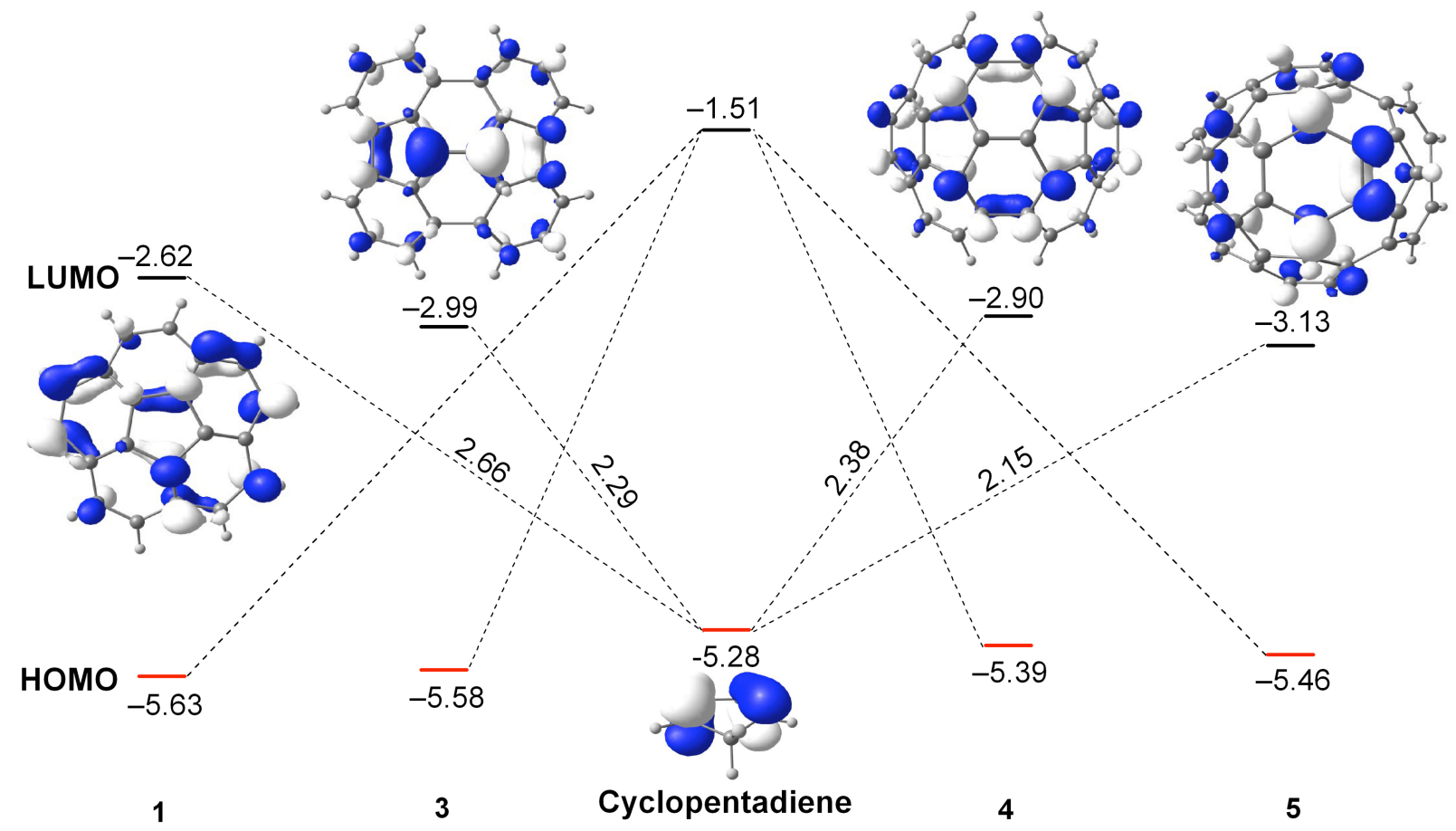

Figure 8. Computed molecular orbitals interaction diagram between cyclopentadiene and the considered buckybowls 1-5 (isosurface value of $0.05 \mathrm{au}$ ). All data have been computed at the BP86-D3/def2-SVP level. 


\section{Conclusions}

From the computational study reported herein, the following five conclusions can be drawn: (i) for all studied buckybowls, the $[6,6]$ attack is both kinetically and thermodynamically favored (with the exception of corannulene) over the $[5,6]$ attack; (ii) starting from corannulene, there is a smooth convergence to the $\mathrm{C}_{60}$ energy barrier for the $[6,6]$ attack when the size of the buckybowl is increased; (iii) we found that there is a good correlation between both the strain energy and TS interaction and energy barriers thus suggesting that not only the deformation required to adopt the corresponding transition state geometry but also the interaction between the deformed reactants are responsible for the observed trend of [4+2]-reactivity of buckybowls; (iv) differently, the major factor responsible for the regioselectivity of this process is the higher interaction between the deformed reactants as a result of higher orbital and electrostatic interactions along the [6,6]-pathway as compared to the corresponding [5,6]-path; and (v), the more stabilizing orbital interactions for the [6,6]-pathway can be attributed to the better HOMOLUMO overlap from the initial reactant complex to the corresponding transition state. Therefore, our main conclusion is that whereas the $[6,6]$-regioselectivity is controlled by the interaction energy between the deformed reactants along the reaction coordinate, the trend of reactivity of buckybowls and $\mathrm{C}_{60}$ depends on the interplay between the strain energy (major factor) and transition state interaction.

\section{Acknowledgments}

We are grateful for financial support from the Spanish MINECO-FEDER (Grants CTQ201344303-P and CTQ2014-51912-REDC to I. F. and CTQ2014-54306-P to M. S.), Fundación BBVA, Catalan DIUE (projects 2014SGR931 and XRQTC to M. S.), the National Research School Combination - Catalysis (NRSC-C), and The Netherlands Organization for Scientific Research (NWO/ALW, NWO/CW, NWO/EW). Support for the research of M. S. was received through the ICREA Academia 2014 prize of the Catalan DIUE. The FEDER grant UNGI10-4E- 
801 (European Fund for Regional Development) has also funded this research. Y. G.-R. acknowledges the MINECO for an FPI grant.

\section{Supporting Information Available}

Cartesian coordinates and total energies of all the stationary points discussed in the text.

\section{References and Notes}

[1]. a) R. Faust, Angew. Chem., Int. Ed. Engl. 1995, 34, 1429; b) P. W. Rabideau, A. Sygula, Acc. Chem. Res. 1996, 29, 235; c) L. T. Scott, Pure Appl. Chem. 1996, 68, 291; d) P. W. Rabideau, A. Sygula, in Advances in Theoretically Interesting Molecules (R. P. Thummel, Ed.), Jai Press Inc.: Greenwich, 1995; vol. 3, pp 1-36; e) M. J. Plater, M. Praveen, D. M. Schmidt, Fullerene Sci. Techn. 1997, 5, 781; f) G. Mehta, H. S. P. Rao Tetrahedron, 1998, 54, 13325; g) L. T. Scott, Angew. Chem. Int. Ed. 2004, 43, 4994; h) S. Higashibayashi, J. Synth. Org. Chem. Jpn. 2009, 67, 38; i) S. Higashibayashi, S. Hidehiro, Chem. Lett. 2011, 40, 122; j) A. Sygula, Eur. J.Org. Chem. 2011, 1611.

[2]. L. T. Scott, H. E. Bronstein, D. V. Preda, R. B. M. Ansems, M. S. Bratcher, S. Hagen, Pure Appl. Chem. 1999, 71, 209-219.

[3]. For a recent nice review: L. T. Scott, Chem. Soc. Rev. 2015, 44, 6464.

[4]. a) A. Hirsch in The Chemistry of the Fullerenes; Thieme: Stuttgart, 1994; b) A. Hirsch and M. Bettreich in Fullerenes, Chemistry and Reactions; Wiley-VCH: Weinheim, 2005; c) N. Martín, M. Altable, S. Filippone, A. Martín-Domenech, Synlett 2007, 3077; d) Fullerenes. Principles and Applications, F. Langa, J.-F. Nierengarten, Eds.; RSC: Cambridge, 2011.

[5]. a) S. Filippone, E. E. Maroto, A. Martín-Domenech, M. Suarez, N. Martín, Nat. Chem. 2009, 1, 578; b) E. E. Maroto, J. Mateos, M. Garcia-Borràs, S. Osuna, S. Filippone, M. A. Herranz, Y. Murata, M. Solà, N. Martín, J. Am. Chem. Soc. 2015, 137, 1190.

[6]. V. M. Tsefrikas, L. T. Scott, Chem. Rev. 2006, 106, 4868.

[7]. Y.-T. Wu, J. S. Siegel, Chem. Rev. 2006, 106, 4843.

[8]. M. A. Petrukhina, L. T. Scott, Eds. Fragments of Fullerenes and Carbon Nanotubes: Designed Synthesis, Unusual Reactions, and Coordination Chemistry; John Wiley \& Sons: Hoboken, 2011. 
[9]. Selected representative examples: a) A. Borchardt, A. Fuchinello, K. V. Kilway, K. K. Baldrige, J. S. Siegel, J. Am. Chem. Soc. 1992, 114, 1921; b) A. H. Abdourazak, A. Sygula, P. W. Rabideau, J. Am. Chem. Soc. 1993, 115, 3010; c) L. T. Scott, M. S. Bratcher, S. Hagen, J. Am. Chem. Soc. 1996, 118, 8473; d) S. Hagen, M. S. Bratcher, M. S. Erickson, G. Zimmermann, L. T. Scott, Angew. Chem, Int. Ed. Engl. 1997, 36, 406; e) A. Sygula, P. W. Rabideau, J. Am. Chem. Soc. 1998, 120, 12666; f) G. Mehta, P. V. V. Srirama Sarma, Chem. Commun. 2000, 19; g) H. E. Bronstein, N. Choi, L. T. Scott, J. Am. Chem. Soc. 2002, 124, 8870; h) E. A. Jackson, B. D. Steinberg, M. Bancu, A. Wakamiya, L. T. Scott, J. Am. Chem. Soc. 2007, 129, 484; i) B. D. Steinberg, E. A. Jackson, A. S. Filatov, A. Wakamiya, M. A. Petrukhina, L. T. Scott, J. Am. Chem. Soc. 2009, 131, 10537; j) L. T. Scott, E. A. Jackson, Q. Zhang, B. D. Steinberg, M. Bancu, B. Li, J. Am. Chem. Soc. 2012, 134, 107; k) H. Y. Cho, R. B. Ansems, L. T. Scott, Beilstein J. Org. Chem. 2014, 10, 956; 1) T. Amaya, T. Ito, T. Hirao, Angew. Chem. Int. Ed. $2015,54,5483$.

[10]. I. Fernández, M. Solà, F. M. Bickelhaupt, Chem. Eur. J. 2013, 19, 7416.

[11]. a) F. M. Bickelhaupt, J. Comput. Chem. 1999, 20, 114. For reviews, see: b) W.-J. van Zeist, F. M. Bickelhaupt, Org. Biomol. Chem. 2010, 8, 3118; c) I. Fernández, F. M. Bickelhaupt, Chem. Soc. Rev. 2014, 43, 4953; d) L. P. Wolters, F. M. Bickelhaupt, WIREs Comput. Mol. Sci. 2015, 5, 324. See also, e) I. Fernández, in Discovering the Future of Molecular Sciences; B. Pignataro, Ed.; pp. 165-187, Wiley-VCH: Weinheim, 2014.

[12]. a) F. M. Bickelhaupt, E. J. Baerends, in Reviews in Computational Chemistry; Lipkowitz, K. B., Boyd, D. B., Eds.; Wiley-VCH: New York, 2000; vol. 15, pp 1-86; b) M. Lein, G. Frenking, G. In Theory and Applications of Computational Chemistry: The First 40 Years; C. E. Dykstra, G. Frenking, K. S. Kim, G. E. Scuseria, Eds.; Elsevier: Amsterdam, 2005, p 291.

[13]. a) M. von Hopffgarten, G. Frenking, WIREs Comput. Mol. Sci. 2012, 2, 43; b) The EDA Perspective of Chemical Bonding" in The Chemical Bond - Fundamental Aspects of Chemical Bonding (Eds.: G. Frenking, S. Shaik), G. Frenking, F. M. Bickelhaupt, pp. 121-158, WileyVCH, Weinheim 2014.

[14]. I. Fernández, M. Solà, F. M. Bickelhaupt, J. Chem. Theory Comput. 2014, 10, 3853.

[15]. F. M. Bickelhaupt, M. Solà, I. Fernández, Chem. Eur. J. 2015, 21, 5760.

[16]. a) S. Osuna, K. N. Houk, Chem. Eur. J. 2009, 15, 13219; b) J. Mestres, M. Solà, J. Org. Chem. 1998, 63, 7556; c) J. Poater, X. Fradera, M. Duran, M. Solà, Chem. Eur. J. 2003, 9, 1113. [17]. a) R. C. Haddon and L. T. Scott, Pure Appl. Chem. 1986, 58, 137; b) R. C. Haddon, J. Am. Chem. Soc. 1987, 109, 1676; c) R. C. Haddon, J. Phys. Chem. 1987, 91, 3719. 
[18]. a) K. Kavitha, M. Manoharan, P. Venuvanalingam, J. Org. Chem. 2005, 70, 2528; b) P. Jayapal, M. Sundararajan, G. Rajaraman, P. Venuvanalingam, R. Kalagi, S. R. Gadre, J. Phys. Org. Chem. 2008, 21,146. For exceptions to this general behavior, see: c) H. E. Bronstein, L. T. Scott, J. Org. Chem. 2008, 73, 88.

[19]. Gaussian 03, Revision E. 01, M. J. Frisch, G. W. Trucks, H. B. Schlegel, G. E. Scuseria, M. A. Robb, J. R. Cheeseman, J. A. Montgomery, Jr., T. Vreven, K. N. Kudin, J. C. Burant, J. M. Millam, S. S. Iyengar, J. Tomasi, V. Barone, B. Mennucci, M. Cossi, G. Scalmani, N. Rega, G. A. Petersson, H. Nakatsuji, M. Hada, M. Ehara, K. Toyota, R. Fukuda, J. Hasegawa, M. Ishida, T. Nakajima, Y. Honda, O. Kitao, H. Nakai, M. Klene, X. Li, J. E. Knox, H. P. Hratchian, J. B. Cross, V. Bakken, C. Adamo, J. Jaramillo, R. Gomperts, R. E. Stratmann, O. Yazyev, A. J. Austin, R. Cammi, C. Pomelli, J. W. Ochterski, P. Y. Ayala, K. Morokuma, G. A. Voth, P. Salvador, J. J. Dannenberg, V. G. Zakrzewski, S. Dapprich, A. D. Daniels, M. C. Strain, O. Farkas, D. K. Malick, A. D. Rabuck, K. Raghavachari, J. B. Foresman, J. V. Ortiz, Q. Cui, A. G. Baboul, S. Clifford, J. Cioslowski, B. B. Stefanov, G. Liu, A. Liashenko, P. Piskorz, I. Komaromi, R. L. Martin, D. J. Fox, T. Keith, M. A. Al-Laham, C. Y. Peng, A. Nanayakkara, M. Challacombe, P. M. W. Gill, B. Johnson, W. Chen, M. W. Wong, C. Gonzalez, and J. A. Pople, Gaussian, Inc., Wallingford CT, 2004.

[20]. R. Ahlrichs, M. Bär, M. Häser, H. Horn, C. Kölmel, Chem. Phys. Lett. 1989, 162, 165.

[21]. a) A. D. Becke, Phys. Rev. A 1988, 38, 3098; b) J. P. Perdew, Phys. Rev. B 1986, 33, 8822 .

[22]. F. Weigend, R. Ahlrichs, Phys. Chem. Chem. Phys. 2005, 7, 3297.

[23]. S. Grimme, J. Antony, S. Ehrlich, H. Krieg, J. Chem. Phys. 2010, 132, 154104.

[24]. K. Eichkorn, O. Treutler, H. Öhm, M. Häser, R. Ahlrichs, Chem. Phys. Lett. 1995, 242, 652.

[25]. a) S. Osuna, M. Swart, M. Solà, J. Phys. Chem. A 2011, 115, 3491; b) M. Garcia-Borràs, J. M. Luis, M. Swart, M. Solà, Chem. Eur. J. 2013, 19, 4468.

[26]. C. González, H. B. Schlegel, J. Phys. Chem. 1990, 94, 5523.

[27]. Selected examples from the Houk group: a) K. N. Houk, R, W. Gandour, R. W. Strozier, N. G. Rondan, L. A. Paquette, J. Am. Chem. Soc. 1979, 101, 6797; b) D. H. Ess, K. N. Houk, J. Am. Chem. Soc. 2007, 129, 10646; c) D. H. Ess, K. N. Houk, J. Am. Chem. Soc. 2008, 130, 10187; d) D. N. Kamber, L. A. Nazarova, Y. Liang, S. A. Lopez, D. M. Patterson, H.-W. Shih, K. N. Houk, J. A. Prescher, J. Am. Chem. Soc. 2013, 135, 13680; e) Yang Cao, Y. Liang, L. Zhang, S. Osuna, A.-L. M. Hoyt, A. L. Briseno, K. N. Houk, J. Am. Chem. Soc. 2014, 136, 
10783; f) J. M. Medina, J. L. Mackey, N. K. Garg, K. N. Houk, J. Am. Chem. Soc. 2014, 136, 15798.

[28]. a) A. P. Bento, F. M. Bickelhaupt, J. Org. Chem. 2007, 72, 2201; b) M. A. van Bochove, M. Swart, F. M. Bickelhaupt, J. Am. Chem. Soc. 2006, 128, 10738; c) A. P. Bento, F. M. Bickelhaupt, J. Org. Chem. 2008, 73, 7290; d) I. Fernández, G. Frenking, E. Uggerud, Chem. Eur. J. 2009, 15, 2166; e) I. Fernández, G. Frenking, E. Uggerud, J. Org. Chem. 2010, 75, 2971; f) I. Fernández, F. M. Bickelhaupt, E. Uggerud, J. Org. Chem. 2013, 78, 8574; g) L. P. Wolters, Y. Ren, F. M. Bickelhaupt, ChemistryOpen, 2014, 3, 29.

[29]. a) I. Fernández, F. M. Bickelhaupt, F. P. Cossío, Chem. Eur. J. 2009, 15, 13022; b) I. Fernández, F. P. Cossío, F. M. Bickelhaupt, J. Org. Chem. 2011, 76, 2310; c) I. Fernández, F. M. Bickelhaupt, J. Comput. Chem. 2012, 33, 509; d) O. Nieto Faza, C. Silva López, I. Fernández, J. Org. Chem. 2013, 78, 5669; e) I. Fernández, F. M. Bickelhaupt, F. P. Cossío, Chem. Eur. J. 2012, 18, 12395; f) I. Fernández, Phys. Chem. Chem. Phys. 2014, 16, 7662; g) I. Fernández, F. M. Bickelhaupt, J. Comput. Chem. 2014, 35, 371; h) I. Fernández, F. M. Bickelhaupt, F. P. Cossío, Chem. Eur.J. 2014, 20, 10791.

[30]. a) W.-J. van Zeist, F. M. Bickelhaupt, Dalton Trans. 2011, 40, 3028 and references therein; b) L. P. Wolters, F. M. Bickelhaupt, ChemistryOpen, 2013, 2, 106; c) A. G. Green, P. Liu, C. A. Merlic, K. N. Houk, J. Am. Chem. Soc. 2014, 136, 4575; d) I. Fernández, K. P. Wolters, F. M. Bickelhaupt, J. Comput. Chem. 2014, 35, 2140; e) E. D. Sosa Carrizo, F. M. Bickelhaupt, I. Fernández, Chem. Eur. J. 2015, doi: 10.1002/chem.201502036.

[31]. E. J. Baerends, J. Autschbach, A. B_erces, J. A. Berger, F. M. Bickelhaupt, C. Bo, P. L. de Boeij, P. M. Boerrigter, L. Cavallo, D. P. Chong, L. Deng, R. M. Dickson, D. E. Ellis, M. van Faassen, L. Fan, T. H. Fischer, C. Fonseca Guerra, S. J. A. van Gisbergen, J. A. Groeneveld, O. V. Gritsenko, M. Grüning, F. E. Harris, P. van den Hoek, C. R. Jacob, H. Jacobsen, L. Jensen, E. S. Kadantsev, G. van Kessel, R. Klooster, F. Kootstra, E. van Lenthe, D. A. McCormack, A. Michalak, J. Neugebauer, V. P. Nicu, V. P. Osinga, S. Patchkovskii, P. H. T. Philipsen, D. Post, C. C. Pye, W. Ravenek, P. Romaniello, P. Ros, P. R. T. Schipper, G. Schreckenbach, J. Snijders, M. Solà, M. Swart, D. Swerhone, G. Te Velde, P. Vernooijs, L. Versluis, L. Visscher, O. Visser, F. Wang, T. A. Wesolowski, E. M. van Wezenbeek, G. Wiesenekker, S. K. Wolff, T. K. Woo, A. L. Yakovlev, T. Ziegler, Computer Code ADF 2013.01; Scientific Computing and Modeling NV: Amsterdam, The Netherlands http://www.scm.com.

[32]. J. G. Snijders, E. J. Baerends, P. Vernoojs, At. Data Nucl. Data Tables 1981, 26, 483. 
[33]. J. Krijn, E. J. Baerends, Fit Functions in the HFS-Method, Internal Report (in Dutch), Vrije Universiteit Amsterdam, The Netherlands, 1984.

[34]. a) E. van Lenthe, E. J. Baerends, J. G. Snijders, J. Chem. Phys. 1993, 99, 4597; b) E. van Lenthe, E. J. Baerends, J. G. Snijders, J. Chem. Phys. 1994, 101, 9783; c) E. van Lenthe, A. Ehlers, E. J. Baerends, J. Chem. Phys. 1999, 110, 8943.

[35]. W. P. Jencks, Chem. Rev. 1985, 85, 511.

[36]. A. E. Hayden, K. N. Houk, J. Am. Chem. Soc. 2009, 131, 4084.

[37]. M. Garcia-Borràs, A. Romero-Rivera, S. Osuna, J. M. Luis, M. Swart, M. Solà, J. Chem. Theory Comput. 2012, 8, 1671.

[38]. M. A. Petrukhina, K. W. Andreini, J. Mack and L. T. Scott, J. Org. Chem. 2005, 70, 5713.

[39]. H. E. Bronstein, N. Choi and L. T. Scott, J. Am. Chem. Soc. 2002, 124, 8870.

[40]. M. A. Petrukhina, K. W. Andreini, L. Peng and L. T. Scott, Angew. Chem., Int. Ed. 2004, 43,5477 .

[41]. D. M. Forkey, S. Attar, B. C. Noll, R. Koerner, M. M. Olmstead and A. L. Balch, J. Am. Chem. Soc. 1997, 119, 5766.

[42]. Cyclopentacorannulene (2) exhibits even a lower HOMO(cyclopentadiene)LUMO(cyclopentacorannulene) gap of only $2.10 \mathrm{eV}$ despite the corresponding computed activation barrier is much higher $\left(\Delta E^{\ddagger}=17.5 \mathrm{kcal} / \mathrm{mol}\right.$, see Table 1$)$.

[43]. a) R. S. Paton, S. Kim, A. G. Ross, S. J. Danishefsky, K. N. Houk, Angew. Chem., Int. Ed. 2011, 50, 10366; b) F. Liu, R. S. Paton, S. Kim, Y. Liang, K. N. Houk, J. Am. Chem. Soc. 2013, 135,15642 .

[44]. a) K. N. Houk, Acc. Chem. Res. 1975, 8, 361; b) D. Biermann, W. Schmidt, J. Am. Chem. Soc. 1980, 102, 3163; c) S. D. Kahn, C. F. Pau, L. E. Overman and W. J. Hehre, J. Am. Chem. Soc. 1986, 108, 7381; d) C. Spino, H. Rezaei and Y. L. Dory, J. Org. Chem. 2004, 69, 757; e) B. R. Ussing, C. Hang and D. A. Singleton, J. Am. Chem. Soc. 2006, 128, 7594.

[45]. A. Talbot, D. Devarajan, S. J. Gustafson, I. Fernández, F. M. Bickelhaupt, D. H. Ess, J. Org. Chem. 2015, 80, 548. 

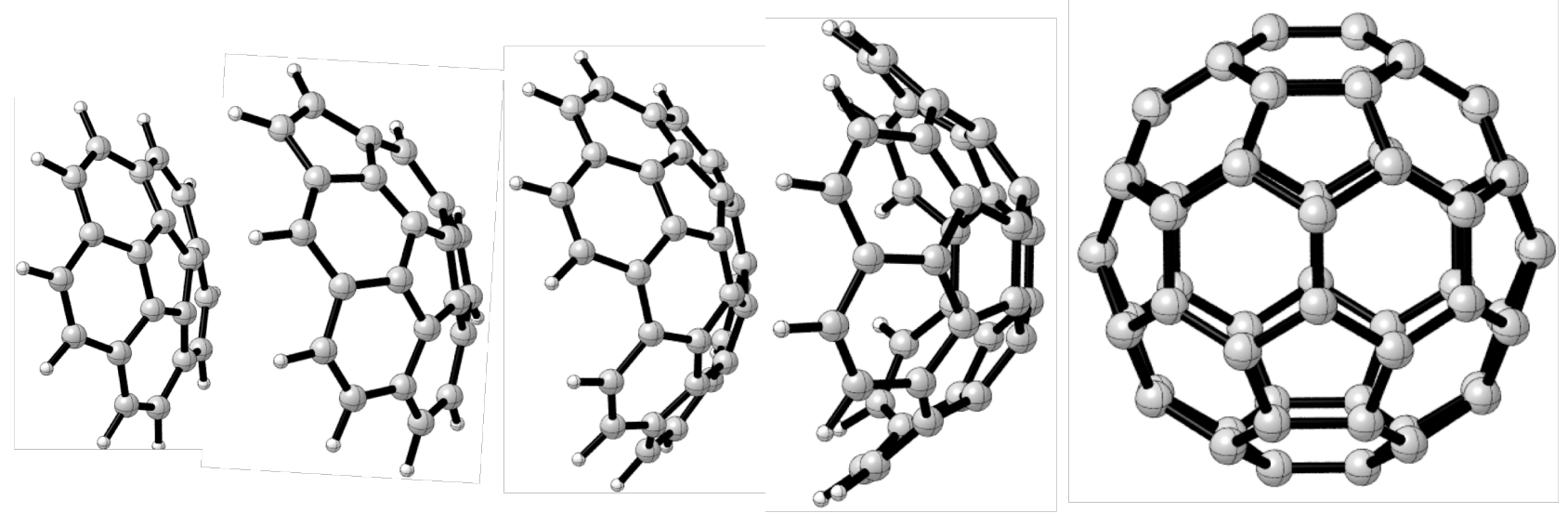

\section{Diels-Alder Reactivity}

$+$

Size matters: Starting from corannulene, there is a smooth convergence to the $\mathrm{C}_{60}$ energy barrier and reaction energy for the Diels-Alder reaction with cyclopentadiene when the size of the buckybowl is increased. By means of the activation strain model of reactivity in combination with the energy decomposition analysis method, the origins of both this trend of reactivity and the observed exclusive [6,6]-regioselectivity are analysed in detail. 